\title{
An easy, convenient and safe process for the synthesis of Lofexidine Hydrochloride
}

Monica Donnola, Annalisa Airoldi, Alessandro Barozza, Jacopo Roletto and Paolo

\author{
Paissoni
}

Research and Development department, CBC Procos S.p.A., Via G.Matteotti 249 ,

Cameri (Novara), 28062, Italy

\section{SUPPORTING INFORMATION}


$\underline{1 \mathrm{H} \text { NMR characterization of ethyl 2-(2,6-dichlorophenoxy)propionate (13) }}$

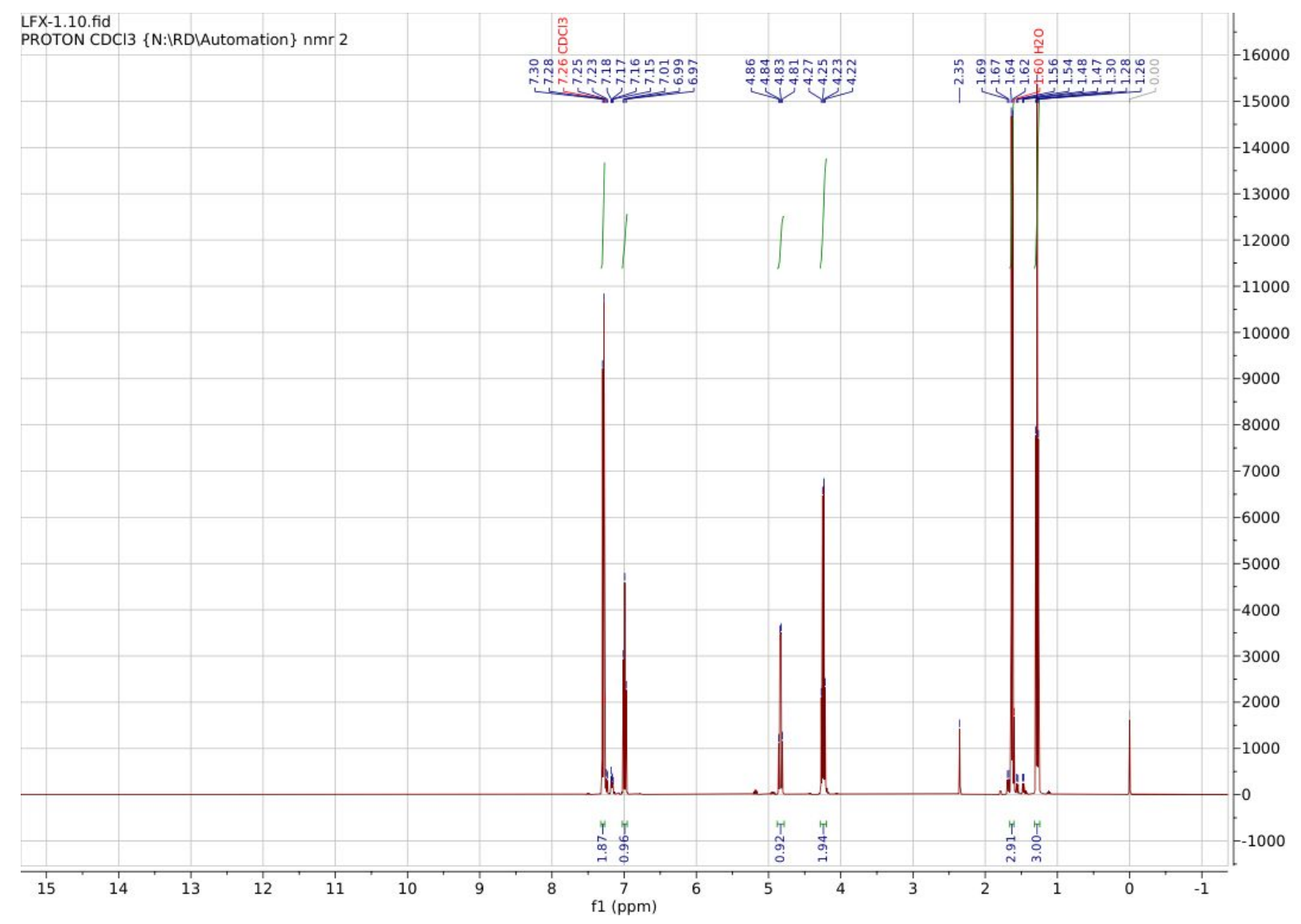


${ }^{13} \mathrm{C}$ NMR characterization of ethyl 2-(2,6-dichlorophenoxy)propionate (13)

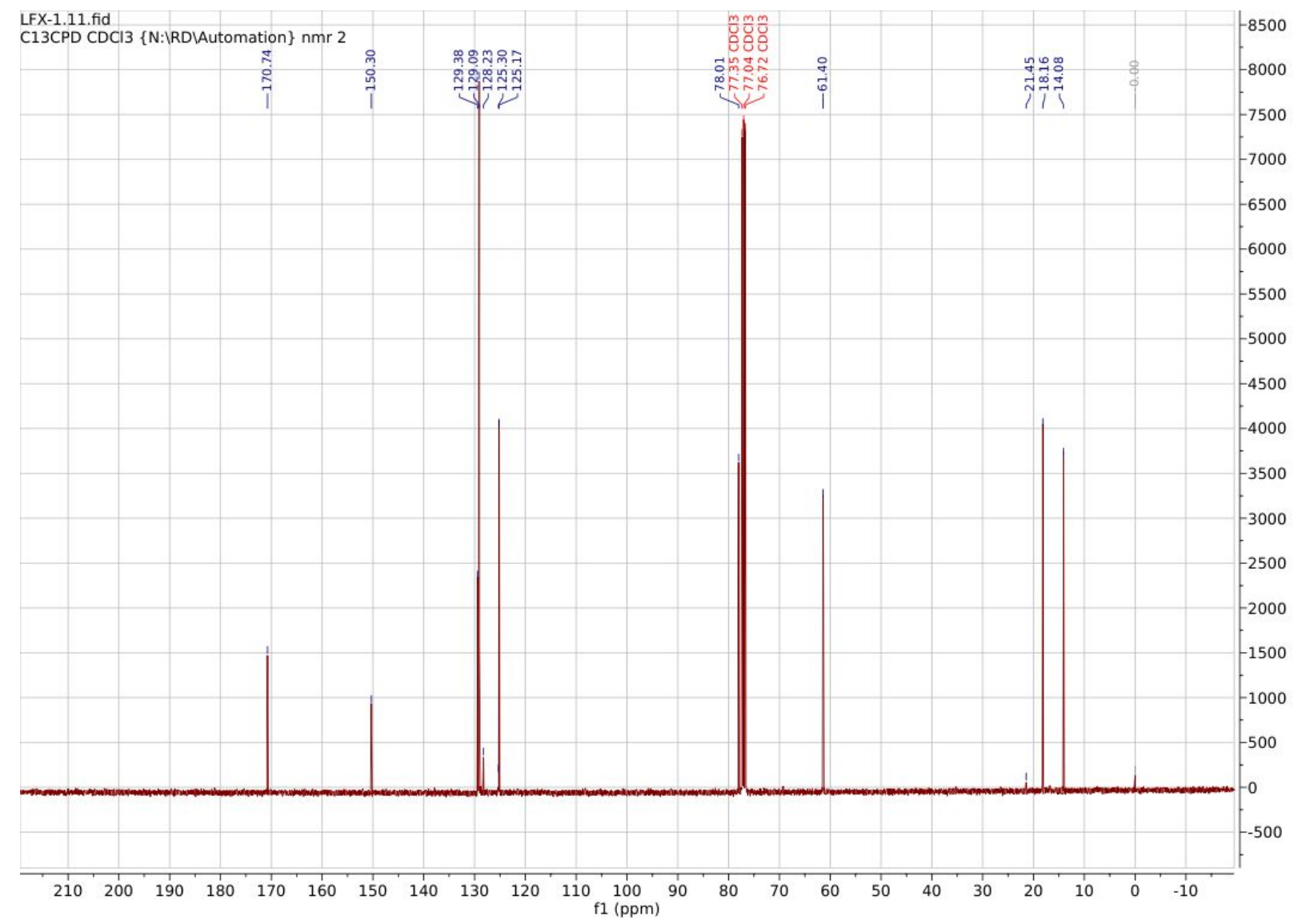


$\underline{1 H}$ NMR characterization of Lofexidine free base

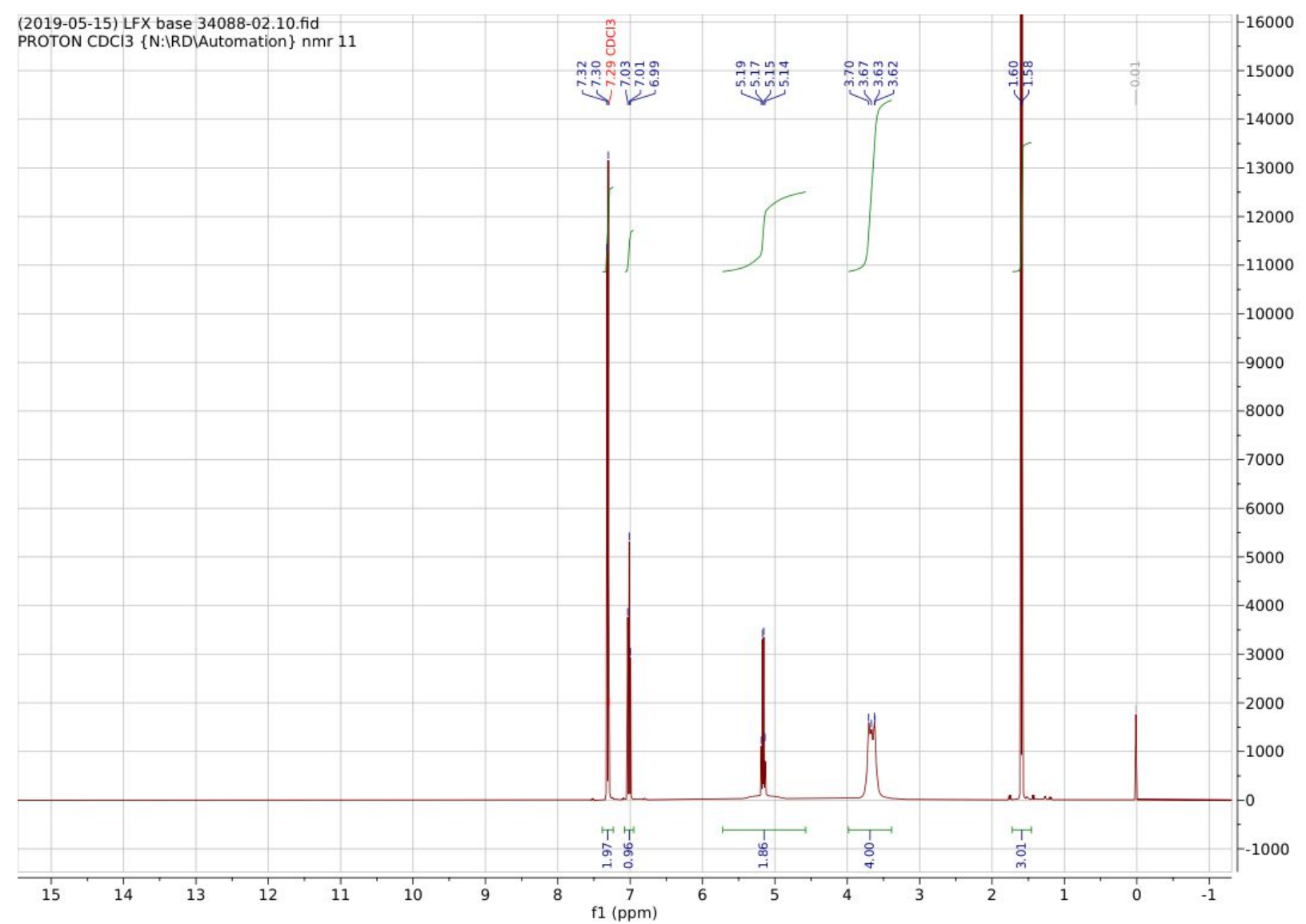


${ }^{13} \mathrm{C}$ NMR characterization of Lofexidine free base

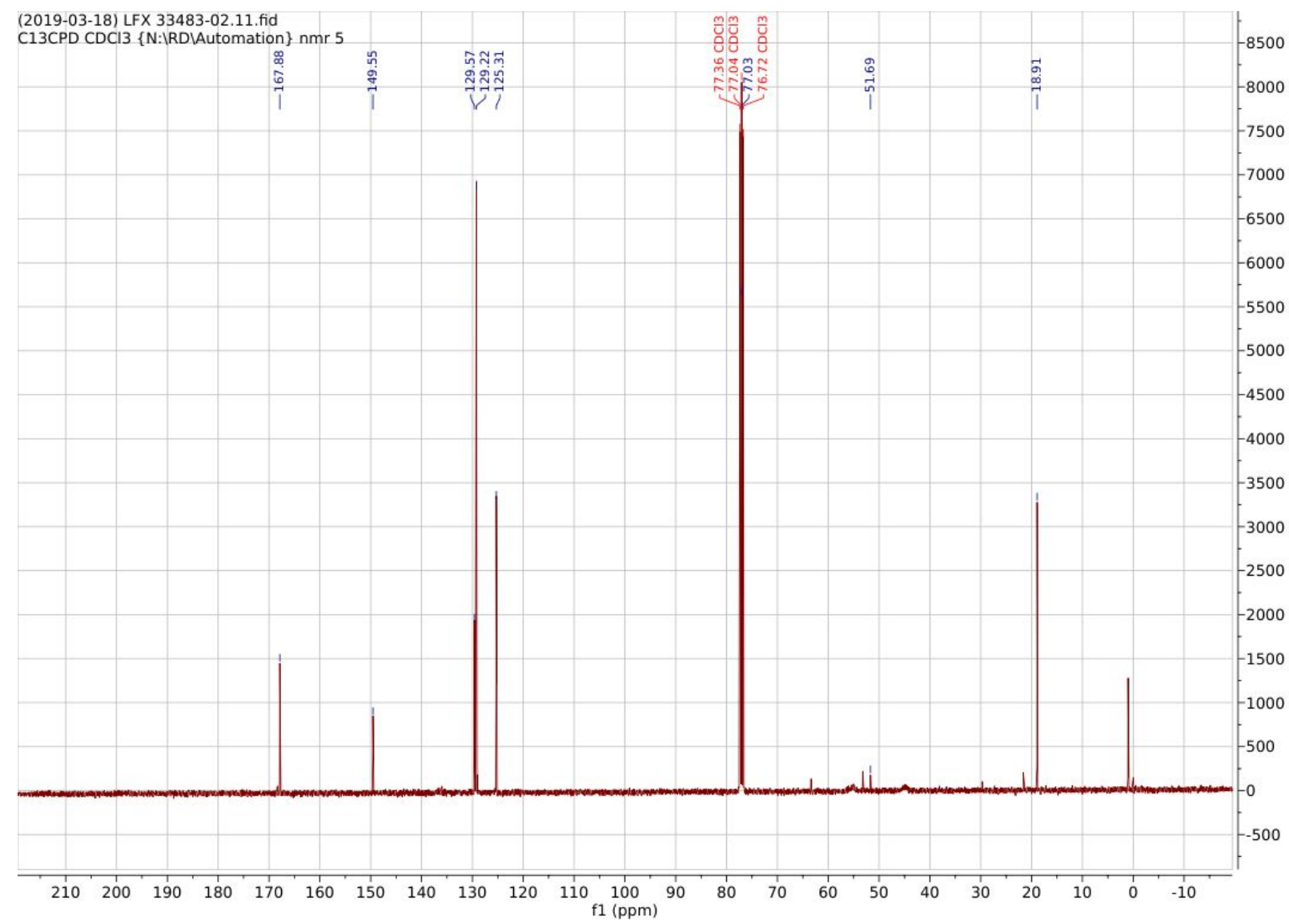


$\underline{{ }^{1} \mathrm{H} \text { NMR of Lofexidine hydrochloride (1) }}$ 


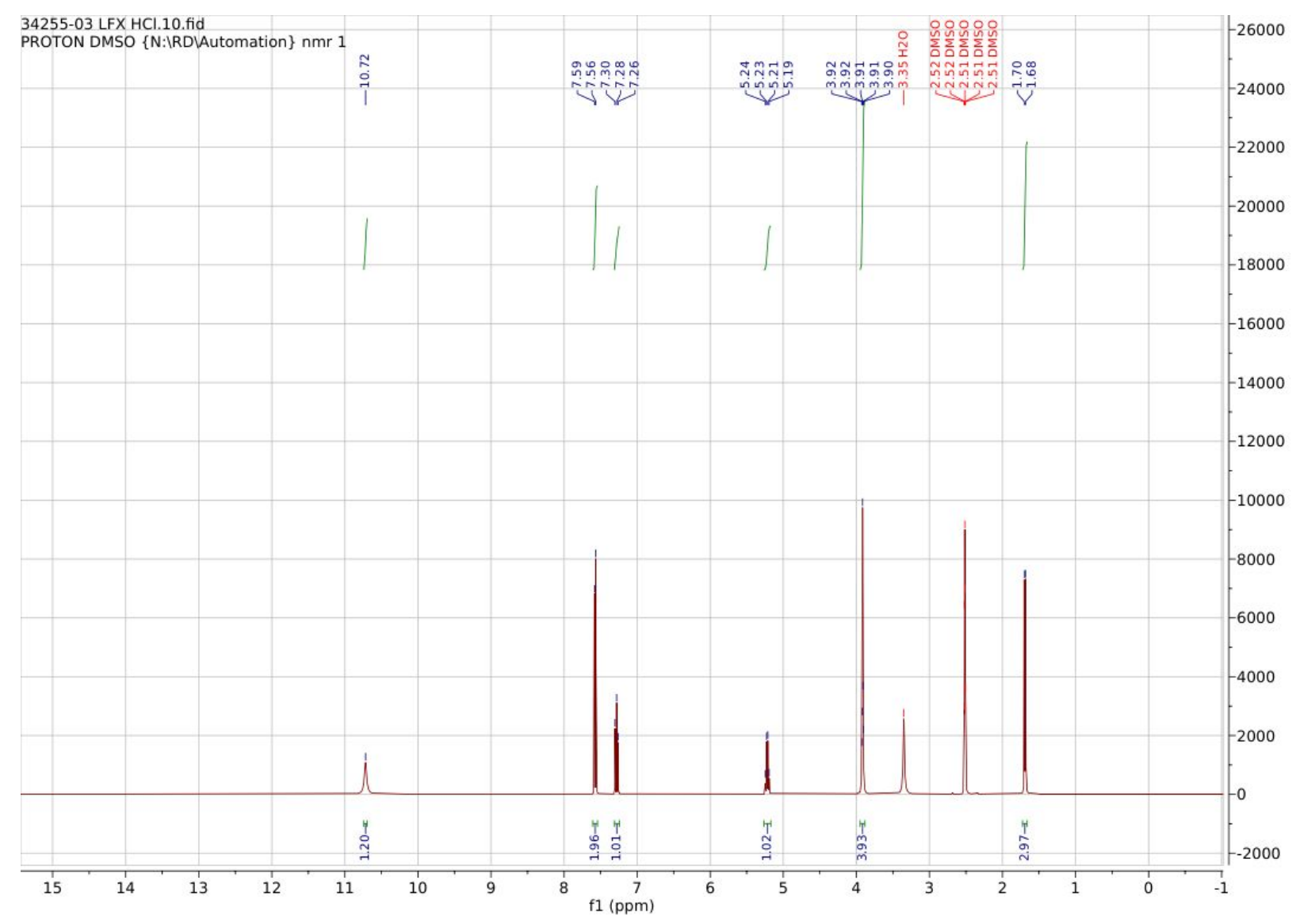


${ }^{13} \mathrm{C}$ NMR of Lofexidine hydrochloride (1)

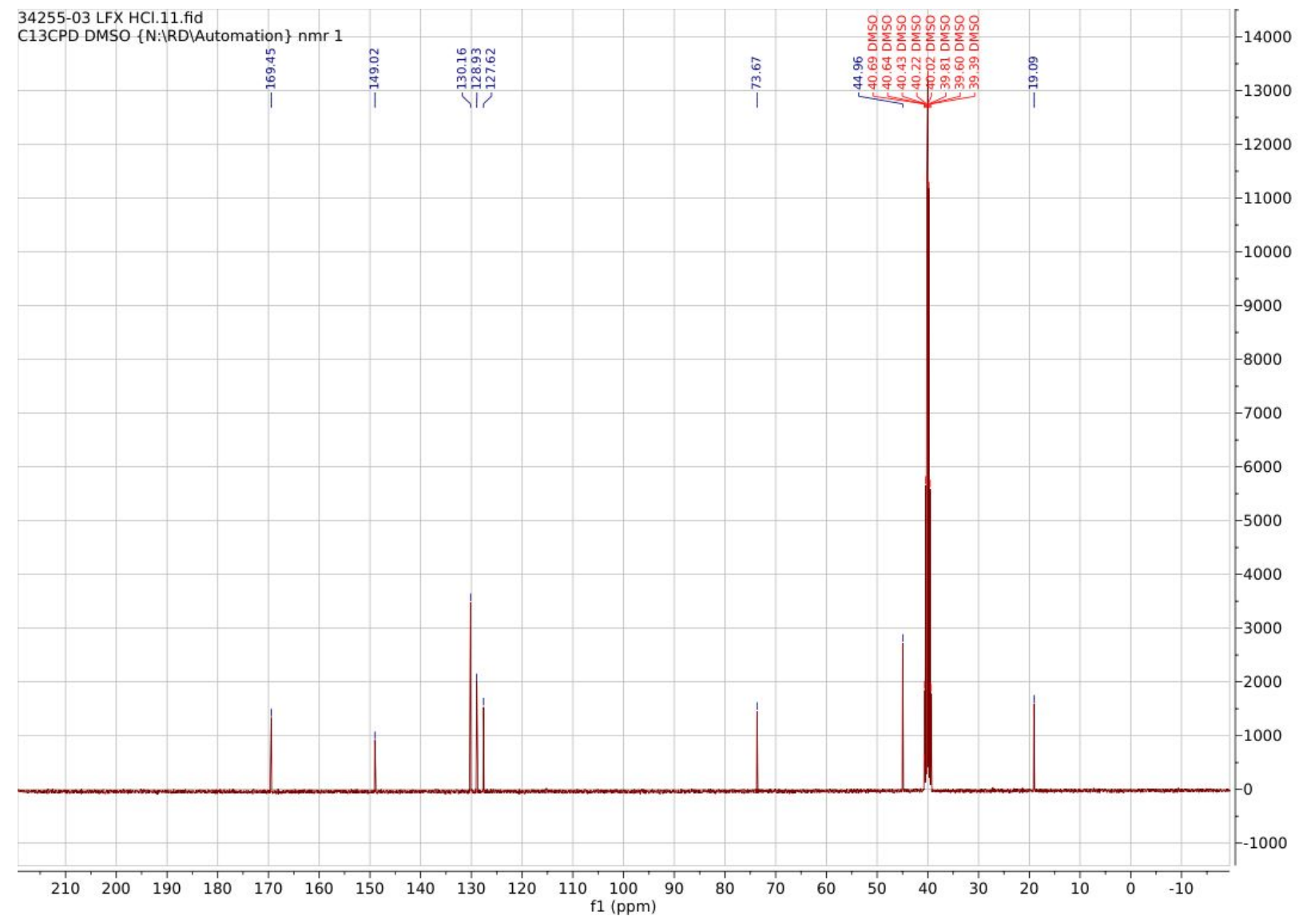

